\title{
Transmissão da Variação da Taxa de Câmbio para os Preços de Exportação Brasileiros do Grão de Soja Um Estudo Comparativo do Dólar e do Euro'
}

\author{
Leonardo Sangoi Copetti², Daniel Arruda Coronel ${ }^{3}$
}

http://dx.doi.org/10.21527/2237-6453.2020.50.166-185

Recebido em: 23/3/2019

Aceito em: 6/9/2019

\begin{abstract}
RESUMO
O objetivo deste trabalho consistiu no exame da relação entre variações cambiais e os preços de exportação brasileiros do grão de soja, relação definida como o pass-through da taxa de câmbio, tendo como referência o período de janeiro de 2000 a dezembro de 2018. Para tanto, estimaram-se dois modelos: em dólar e em euro. Os dados foram coletados nos sites do Instituto de Economia Aplicada - Ipea - e no World Bank. Neste sentido, fez-se uso dos instrumentais de séries temporais, especialmente do Modelo Vetor de Correção de Erros. Os resultados encontrados forneceram indicações de que o grau de pass-through da taxa de câmbio para os preços de exportação do grão de soja ocorreu de forma incompleta, com os coeficientes para dólar e euro de, respectivamente, -0,29 e -0,33, representando que depreciações da taxa de câmbio não se traduzem em ganhos significativos de competitividade, dado que não reduzem expressivamente os preços de exportação.
\end{abstract}

Palavras-chave: Grão de soja. Preços de exportação. Pass-Through.

TRANSMISSION OF EXCHANGE RATE VARIATION FOR BRAZILIAN SOYBEAN GRAIN EXPORT PRICES: A COMPARATIVE STUDY OF DOLLAR AND EURO

\section{ABSTRACT}

The aim of this work consisted in the relation exam between exchange rate variations and the Brazilian soybean grain export prices, relation defined as the pass-through of exchange rate, having as reference the period from January, 2000 until December, 2018. For this, we estimated two models: in dollar and in euro. The data was collected from the sites of Institute for Applied Economic Research - Ipea and World Bank. In this sense, we used instrumental of time series, especially of the Vector Error Correction Model. The results found provided indications that the degree of pass-through of the exchange rate for the soybean grain export prices occurred in a incomplete way, with the coefficient for dollar and euro of, respectively, -0.29 and -0.33 , representing that depreciations of the exchange rate do not translate themselves in significant gains of competitiveness, since that they do not reduce expressively the export prices.

Keywords: Soybean grain. Export prices. Pass-Through.

\footnotetext{
${ }^{1}$ Este artigo faz parte de uma pesquisa a qual visa a estudar a relação entre variações cambiais em dólar e em euro e os preços de exportação brasileiros do grão, farelo e óleo de soja e conta com o apoio do CNPq, por meio da chamada Universal-2018.

${ }^{2}$ Mestre em Administração pela Universidade Federal de Santa Maria (UFSM). leonardocopetti@hotmail.com

${ }^{3}$ Doutor em Economia Aplicada pela Universidade Federal de Viçosa (UFV). Professor da Universidade Federal de Santa Maria (UFSM). daniel.coronel@uol.com.br
} 
Segundo o United States Department of Agriculture - Usda (2019), o Brasil é o maior exportador mundial do grão de soja, visto que na safra 2018/2019 o total exportado foi de 79,5 milhões de toneladas, o que representou $51,62 \%$ das exportações mundiais, que foram de 154 milhões de toneladas.

Além disso, para o Ministério do Desenvolvimento, Indústria e Comércio Exterior (MDIC, 2019), o total do grão de soja exportado pelo Brasil em 2018 foi de US\$ 33,19 bilhões, o que representou $13,84 \%$ das exportações totais do país. Em comparação com o ano de 2000 , houve um incremento de $1.416 \%$ do faturamento das exportações desta commodity, observando-se que as exportações nesse ano foram de US\$2,19 bilhões.

Segundo Ferreira e Sanso (1999), países que fizeram tardiamente seu processo de industrialização, como o Brasil, são geralmente considerados com pouco controle sobre os preços que vendem nos mercados internacionais. Dessa forma, as variações na taxa de câmbio podem ter pouca relevância na determinação dos preços de exportação, ou seja, o coeficiente de pass-through tende a ser nulo.

Diante deste contexto, o problema de pesquisa deste trabalho é responder à seguinte questão: Existe diferença entre o grau de pass-through para os preços de exportação brasileiros do grão de soja entre as taxas de câmbio real/dólar e real/euro, no período compreendido entre $1 / 2000$ e 12/2018?

A partir do desenvolvimento deste estudo têm-se elementos que auxiliam na compreensão da magnitude com que se dá a transmissão de preços para o mercado do grão da soja, bem como para entender mais sobre como a política econômica e cambial pode impactar sobre a competitividade do exportador brasileiro.

$\mathrm{O}$ presente trabalho está estruturado em três seções, além desta introdução. $\mathrm{Na}$ segunda seção são apresentados os estudos empíricos realizados sobre a transmissão de preços e o coeficiente de pass-through no mercado brasileiro; na terceira são expostos os procedimentos metodológicos esboçados; na seção seguinte os resultados são analisados e discutidos e, por fim, na última seção, são apresentadas as principais conclusões do trabalho.

\section{TRANSMISSÃO DE PREÇOS E COEFICIENTE DE PASS-THROUGH NO MERCADO BRASILEIRO}

Margarido, Turolla e Fernandes (2001) analisaram a elasticidade da transmissão de preços no mercado de grão de soja entre o porto de Rotterdã e o Brasil, no período de julho de 1994 e setembro de 2000. Para tanto, utilizaram-se de econometria de séries temporais e do modelo Vetorial de Correção de Erros - VEC. Como resultados, os autores estimaram um coeficiente de longo prazo para o Porto de Rotterdã de -1,19311, indicando uma relação elástica e a transferência, mais que proporcionalmente, em torno de $119,31 \%$ das variações nos preços da soja em Rotterdã para os preços domésticos no Brasil. Além disso, o coeficiente da taxa de câmbio nominal foi de -1,03867, representando que as variações na taxa de câmbio nominal são transferidas em aproximadamente 103,87\% para os preços domésticos no Brasil.

Margarido, Fernandes e Turolla (2002) utilizaram o modelo de Mundlack e Larson (1992), baseado na Lei do Preço Único, com a finalidade de estimar a elasticidade de transmissão de preços entre os mercados do Brasil (preço FOB) e o porto de Rotterdã 
(preço CIF), no período de julho de 1994 a setembro de 2001. Para isso utilizam-se de econometria de séries temporais (estacionariedade - teste ADF, causalidade de Granger, cointegração de Johansen e modelo vetorial de correção de erros - VEC). Como resultado, os autores estimaram um coeficiente de longo prazo de $-0,98148$ para o porto de Rotterdã, indicando que as variações no mercado externo são transmitidas integralmente para os preços FOB do grão da soja no mercado brasileiro.

Cruz Jr. e Silva (2004) estudaram o coeficiente de pass-through para a exportação trimestral dos produtos agropecuários brasileiros no período compreendido entre o $3^{\circ}$ trimestre de 1994 e o $2^{\circ}$ trimestre 2003. Foram utilizadas as seguintes séries para a estimação do modelo: o índice de preços de exportação para produtos agropecuários do Brasil, o índice de preços de atacado para lavouras de exportação (IPA-OG) como proxy para o custo de produção, a taxa de câmbio nominal (real/dólar) fim do período, e, para o preço internacional, foi utilizada série de preços de importação de commodities dos Estados Unidos. Os autores utilizaram-se de econometria de séries temporais e do modelo Vetorial de Correção de Erros - VEC. Como resultado, estimaram um coeficiente de pass-through de $-0,53$, representando que as variações da taxa de câmbio afetam parcialmente o preço de exportação dos produtos agropecuários brasileiros.

Margarido, Turolla e Bueno (2007) analisaram a transmissão de preços do grão da soja entre os mercados europeu, brasileiro, argentino e americano, no período de outubro de 1995 até outubro de 2003. Nesse sentido, utilizaram-se de econometria de séries temporais e do modelo Vetorial de Correção de Erros - VEC. Como resultados, encontraram que as variações no mercado internacional do preço da soja tendem a ser totalmente transmitidas aos preços no Brasil, no longo prazo, de modo que a elasticidade do preço de transmissão é a unidade. Outra importante conclusão do estudo foi a de que Brasil e Argentina apresentaram-se como mercados tomadores de preços, já o porto de Rotterdã e os Estados Unidos foram apontados como formadores de preços.

Tejada e Silva (2008) analisaram a relação entre as variações da taxa de câmbio e os preços dos principais produtos exportados pelo Brasil, com dados trimestrais, de janeiro de 1980 a janeiro de 2004. Os setores pesquisados e as respectivas participações no ano de 2004 foram Peças e Outros Veículos (10,29\%), Siderurgia (7,11\%), Extrativa Mineral (8,41\%), Máquinas e Tratores - MAQ (5,33\%), Veículos Automotores $(5,05 \%)$, Óleos Vegetais (4,96\%), Refino de Petróleo (4,55\%), Madeira e Mobiliário $(4,14 \%)$, Beneficiamento de Produtos Vegetais (3,22\%), Metalurgia de Não Ferrosos (3,16\%), Celulose Papel e Gráfica (3,06\%), Material Elétrico (2,34\%), Elementos Quími$\cos (2,15 \%)$ e Equipamentos Eletrônicos (2,10\%). Para estimar o coeficiente de pass-through os autores utilizaram o filtro de Kalman, gerando um coeficiente variável ao longo do tempo. Como resultados da pesquisa os setores pesquisados apresentaram um coeficiente de pass-through oscilando entre zero e -1 (menos um), indicando pass-through incompleto, ou seja, a variação da taxa de câmbio afeta parcialmente os preços de exportação.

Fraga et al. (2008) investigaram o repasse da variação da taxa de câmbio para os preços mensais de exportação da soja em grão do Brasil no período de julho de 1994 a dezembro de 2004. Para tanto, os autores utilizaram testes de raiz unitária (ADF), de cointegração de Johansen e modelo Vetorial de Correção de Erros (VEC). Como resultados, estimaram um coeficiente de pass-through no valor de -0,34, representando um 
pass-through incompleto, ou seja, que a política cambial adotada pelo país reflete-se nos lucros do exportador: se o câmbio é apreciado, o exportador é obrigado a cumprir seus lucros; do contrário, quando o câmbio é depreciado, o exportador expande seus lucros.

Correa (2012) analisou o impacto das variações cambiais sobre as exportações de 26 setores da economia brasileira, no período de 1995 a 2005. Os setores pesquisados foram extrativa mineral, extração de petróleo e gás, minerais não metálicos, siderurgia, metalurgia dos não ferrosos, outros produtos metalúrgicos, fabricação de máquinas e tratores, material elétrico, equipamentos eletrônicos, automóveis, outros veículos e peças, madeira e mobiliário, papel e gráfica, indústria da borracha, elementos químicos não petroquímicos, refino de petróleo e petroquímica, fabricação de produtos químicos diversos, indústria têxtil, fabricação de artigos de couro e calçados, indústria do café, beneficiamento de produtos vegetais, abate de animais, indústria do açúcar, fabricação de gorduras e óleos vegetais, outros produtos alimentares e bebidas e indústrias diversas. As variáveis utilizadas no modelo econométrico foram o preço das exportações brasileiras de 26 setores classificados pelo Instituto Brasileiro de Geografia e Estatística (IBGE), a taxa de câmbio nominal, o custo doméstico utilizando uma metodologia para custo setorial, o preço das exportações concorrentes internacionais correspondendo ao índice de preços das importações norte-americanas e o grau de utilização da capacidade instalada calculada pela Fundação Getulio Vargas - FGV. Como resultados, o autor apresentou coeficientes de pass-through incompletos para os diversos setores pesquisados.

Margarido (2012) investigou a transmissão espacial de preços no mercado internacional do grão da soja de Brasil, Argentina e Rotterdã, no período de outubro de 1998 a dezembro de 2009. Para tanto, utilizou-se de econometria de séries temporais e do modelo Vetorial de Correção de Erros - VEC, empregando o modelo de transmissão espacial de preços desenvolvido por Ravallion (1986). Como resultados, o autor identificou que as variações dos preços internacionais do grão de soja (Rotterdã) são transmitidas integralmente ao mercado brasileiro.

Copetti, Vieira e Coronel (2012) realizaram pesquisa sobre a transmissão da variação da taxa de câmbio aos preços de exportação do grão de soja no Brasil e na Argentina, no período de 3/1999 a 2/2011. Para tanto, utilizaram-se de econometria de séries temporais e do modelo Vetorial de Correção de Erros - VEC. Os resultados revelaram um coeficiente de pass-through incompleto para o Brasil $(-0,11)$ e nulo para Argentina. No mercado brasileiro, a estimativa do coeficiente indicou que a variação da taxa de câmbio exerce influência parcial sobre os preços médios de exportação do grão de soja, ou seja, o aumento de $1 \%$ na taxa de câmbio ocasiona um aumento de $0,11 \%$ no preço médio de exportação do grão de soja no Brasil. Já para o mercado argentino, as variações da taxa de câmbio não exercem influência sobre os preços médios de exportação do grão de soja.

Outro estudo desenvolvido por Copetti, Vieira e Coronel (2013) analisou o relacionamento da taxa de câmbio (real/euro - R\$/€) e os preços de exportação do grão de soja entre Estados Unidos, Brasil e Argentina (em euro/toneladas - $€$ /toneladas) no período de janeiro de 2003 a janeiro de 2012. Para tanto, os autores usaram testes de estacionariedade das séries (ADF e KPSS), o teste de cointegração de Johansen e o modelo Vetorial de Correção de Erros - VEC. Como resultados, foram identificados 
um coeficiente de pass-through incompleto para os Estados Unidos e coeficientes nulos para o Brasil e a Argentina. No mercado norte-americano o coeficiente de $-0,65$ indica influência parcial da variação na taxa de câmbio (dólar/euro - US\$/€) sobre o preço de exportação do grão de soja ( $€$ /toneladas), e uma variação de $0,65 \%$ no mesmo sentido do preço de exportação do grão de soja produzida pela variação de $1 \%$ na taxa de câmbio. Nos mercados brasileiro e argentino, entretanto, a variação da taxa de câmbio não exerce influência sobre os preços de exportação do grão de soja.

Souza (2018) buscou avaliar a influência das variações cambiais no desempenho exportador do milho e do algodão considerando dados mensais de janeiro de 2002 a dezembro de 2016. Para estimar o pass-through da taxa de câmbio para os preços de exportação do milho e do algodão, o autor empregou o Modelo Vetorial de Correção de Erro e o Modelo Estrutural Vetorial de Correção de Erro. Os resultados mostraram que o pass-through da taxa de câmbio para o preço de exportação do milho foi incompleto, significando que as variações cambiais afetaram a competitividade do exportador dessa cultura. No caso do algodão, o pass-through para o seu preço de exportação foi nulo, indicando que as variações cambiais agiram impactando apenas o mark-up do exportador dessa commodity.

Souza, Raniro e Rosa (2018) avaliaram o pass-through da taxa de câmbio para os preços de exportações, em dólares e em reais, do açúcar brasileiro de janeiro de 2012 a dezembro de 2016. Utilizaram as ferramentas econométricas de séries temporais multivariadas, com destaque para o Modelo Vetorial de Correção de Erro. Os resultados apontaram um pass-through incompleto da taxa de câmbio para os preços de exportações do açúcar, em dólares e em reais, tendo baixo coeficiente $(-0,03)$ de pass-through cambial para o preço em dólares e alto coeficiente $(0,97)$ para o preço em reais.

No Quadro 1 faz-se uma síntese dos estudos sobre transmissão de preços e coeficiente de pass-through nas exportações brasileiras.

Quadro 1 - Síntese dos estudos empíricos

\begin{tabular}{|c|c|c|c|c|c|}
\hline Autores & $\begin{array}{c}\text { País / paí- } \\
\text { ses }\end{array}$ & Período & Produtos & $\begin{array}{c}\text { Metodologia/ ob- } \\
\text { jetivo do estudo }\end{array}$ & Resultados \\
\hline $\begin{array}{c}\text { Margarido, } \\
\text { Turolla e Fer- } \\
\text { nandes (2001) }\end{array}$ & Brasil & $\begin{array}{c}7 / 1994- \\
9 / 2000\end{array}$ & grão de soja & $\begin{array}{c}\text { Modelo Vetorial } \\
\text { de Correção de } \\
\text { Erros/ elasticidade } \\
\text { de transmissão de } \\
\text { preços internacio- } \\
\text { nal }\end{array}$ & $\begin{array}{c}\text { coeficiente elásti- } \\
\text { co (-1,19311) }\end{array}$ \\
\hline $\begin{array}{c}\text { Margarido, } \\
\text { Fernandes e } \\
\text { Turolla (2002) }\end{array}$ & Brasil & $\begin{array}{c}7 / 1994- \\
9 / 2001\end{array}$ & grão de sojaj & $\begin{array}{c}\text { Modelo Vetorial } \\
\text { de Correção de } \\
\text { Erros/ elasticidade } \\
\text { de transmissão de } \\
\text { preços internacio- } \\
\text { nal }\end{array}$ & $\begin{array}{c}\text { coeficiente elásti- } \\
\text { co (-0,98148) }\end{array}$ \\
\hline $\begin{array}{c}\text { Cruz Jr. e Silva } \\
\text { (2004) }\end{array}$ & Brasil & $\begin{array}{c}3^{\circ} \text { trim./ } \\
1994- \\
2^{\circ} \text { trim./ } \\
2003\end{array}$ & $\begin{array}{c}\text { produtos } \\
\text { agropecuá- } \\
\text { rios }\end{array}$ & $\begin{array}{c}\text { Modelo Vetorial de } \\
\text { Correção de Erros/ } \\
\text { coeficiente de pas- } \\
\text { s-through }\end{array}$ & pass-through in- \\
completo (-0,53)
\end{tabular}




\begin{tabular}{|c|c|c|c|c|c|}
\hline $\begin{array}{l}\text { Margarido, Tu- } \\
\text { rolla e Bueno } \\
\text { (2007) }\end{array}$ & $\begin{array}{l}\text { Brasil, } \\
\text { Argentina } \\
\text { e Estados } \\
\text { Unidos }\end{array}$ & $\begin{array}{l}10 / 1995- \\
10 / 2003\end{array}$ & grão de soja & $\begin{array}{c}\text { Modelo Vetorial } \\
\text { de Correção de } \\
\text { Erros/ elasticidade } \\
\text { de transmissão de } \\
\text { preços internacio- } \\
\text { nal } \\
\end{array}$ & $\begin{array}{l}\text { coeficiente elásti- } \\
\text { co (unidade) }\end{array}$ \\
\hline $\begin{array}{l}\text { Tejada e Silva } \\
\text { (2008) }\end{array}$ & Brasil & $\begin{array}{l}1 / 1980- \\
1 / 2004\end{array}$ & $\begin{array}{l}\text { exportações } \\
\text { setoriais }\end{array}$ & $\begin{array}{c}\text { filtro de Kalman/ } \\
\text { coeficiente de pas- } \\
\text { s-through }\end{array}$ & $\begin{array}{l}\text { pass-through in- } \\
\text { completo (entre } \\
\text {-1 e zero) }\end{array}$ \\
\hline $\begin{array}{l}\text { Fraga et al. } \\
\text { (2008) }\end{array}$ & Brasil & $\begin{array}{l}7 / 1994- \\
12 / 2004\end{array}$ & grão de soja & $\begin{array}{c}\text { Modelo Vetorial de } \\
\text { Correção de Erros/ } \\
\text { coeficiente de pas- } \\
\text { s-through } \\
\end{array}$ & $\begin{array}{l}\text { pass-through in- } \\
\text { completo }(-0,34)\end{array}$ \\
\hline $\begin{array}{l}\text { Margarido } \\
\text { (2012) }\end{array}$ & $\begin{array}{c}\text { Brasil e } \\
\text { Argentina }\end{array}$ & $\begin{array}{l}10 / 1998- \\
10 / 2009\end{array}$ & grão de soja & $\begin{array}{l}\text { Modelo Vetorial } \\
\text { de Correção de } \\
\text { Erros/ elasticidade } \\
\text { de transmissão } \\
\text { espacial de preços } \\
\text { internacional }\end{array}$ & $\begin{array}{l}\text { transmissão inte- } \\
\text { gral da variação } \\
\text { dos preços inter- } \\
\text { nacionais do grão } \\
\text { de soja ao mer- } \\
\text { cado brasileiro }\end{array}$ \\
\hline Correa (2012) & Brasil & $\begin{array}{l}1995- \\
2005\end{array}$ & $\begin{array}{l}\text { exportações } \\
\text { setoriais }\end{array}$ & $\begin{array}{c}\text { Econometria de } \\
\text { séries temporais/ } \\
\text { coeficiente de pas- } \\
s \text {-through }\end{array}$ & $\begin{array}{l}\text { pass-through } \\
\text { incompleto para } \\
\text { os setores pes- } \\
\text { quisados } \\
\end{array}$ \\
\hline $\begin{array}{l}\text { Copetti, Viei- } \\
\text { ra e Coronel } \\
\quad(2012)\end{array}$ & $\begin{array}{c}\text { Brasil e } \\
\text { Argentina }\end{array}$ & $\begin{array}{l}3 / 1999- \\
2 / 2011\end{array}$ & grão de soja & $\begin{array}{c}\text { Modelo Vetorial de } \\
\text { Correção de Erros/ } \\
\text { coeficiente de pas- } \\
\text { s-through }\end{array}$ & $\begin{array}{l}\text { pass-through in- } \\
\text { completo }(-0,11)\end{array}$ \\
\hline $\begin{array}{l}\text { Copetti, Viei- } \\
\text { ra e Coronel } \\
\text { (2013) }\end{array}$ & $\begin{array}{l}\text { Estados } \\
\text { Unidos, } \\
\text { Brasil e } \\
\text { Argentina }\end{array}$ & $\begin{array}{l}1 / 2003- \\
1 / 2012\end{array}$ & grão de soja & $\begin{array}{l}\text { Modelo Vetorial de } \\
\text { Correção de Erros/ } \\
\text { coeficiente de pas- } \\
\text { s-through }\end{array}$ & $\begin{array}{l}\text { pass-through } \\
\text { nulo }\end{array}$ \\
\hline Souza (2018) & Brasil & $\begin{array}{l}1 / 2002- \\
12 / 2016\end{array}$ & $\begin{array}{l}\text { milho e algo- } \\
\text { dão }\end{array}$ & $\begin{array}{c}\text { Modelo Vetorial } \\
\text { de Correção de } \\
\text { Erros/ Modelo Es- } \\
\text { trutural Vetorial de } \\
\text { Correção de Erro/ } \\
\text { coeficiente de pas- } \\
\text { s-through } \\
\end{array}$ & $\begin{array}{l}\text { pass-through in- } \\
\text { completo para o } \\
\text { milho e nulo para } \\
\text { o algodão }\end{array}$ \\
\hline $\begin{array}{l}\text { Souza, Raniro } \\
\text { e Rosa (2018) }\end{array}$ & Brasil & $\begin{array}{l}1 / 2012- \\
12 / 2016\end{array}$ & açúcar & $\begin{array}{c}\text { Modelo Vetorial de } \\
\text { Correção de Erros/ } \\
\text { coeficiente de pas- } \\
\text { s-through }\end{array}$ & $\begin{array}{c}\text { baixo coeficiente } \\
(-0,03) \text { de pass- } \\
\text {-through cambial } \\
\text { para os preços } \\
\text { em dólares e alto } \\
\text { coeficiente }(0,97) \\
\text { para o preço em } \\
\text { reais }\end{array}$ \\
\hline
\end{tabular}

Fonte: Organização dos autores.

Nesta subseção foram reunidos estudos realizados sobre transmissão de preços e coeficiente de pass-through nas exportações brasileiras a fim de analisar a relação entre a taxa de câmbio e os preços de exportação do Brasil, bem como a transmissão de preços internacionais aos preços domésticos e de exportação brasileiros do grão de soja. 
Os estudos supracitados revelaram que o Brasil apresentou um coeficiente de pass-through incompleto nas exportações (entre zero e -1) e nulo e que a transmissão de preços internacionais do açúcar aos preços domésticos comportou-se de forma elástica, ou seja, os preços internacionais são transmitidos integralmente aos preços domésticos. A presente pesquisa difere dos estudos citados pelo comparativo do coeficiente de pass-through nas exportações do grão de soja em dólar e em euro.

\section{METODOLOGIA}

\section{Modelo Analítico}

O modelo econométrico pass-through, de acordo com Menon (1995), usado em sua forma mais simples, parte de um modelo de mark-up que pode ser representado da seguinte forma:

$$
P^{*} X=(1+\lambda)(C P / E)
$$

em que; $P^{*} X$ é o preço de exportação em moeda estrangeira; $(C P / E)$ é custo de produção, medido em moeda estrangeira; $E$ é a taxa de câmbio nominal; e $\lambda$ é mark-up.

Partindo-se do pressuposto de que o mark-up pode variar de acordo com a pressão competitiva no mercado mundial, tem-se que:

$$
(1+\lambda)=\left[\frac{P W}{C P / E}\right]^{\alpha}
$$

com $[P W /(C P / E)]$ correspondendo à diferença entre o preço das exportações mundiais e o custo de produção do exportador medido em moeda estrangeira.

Substituindo a Equação (2) em (1) e aplicando-se o logaritmo neperiano no resultado dessa substituição, chega-se à seguinte equação de preço de exportação em moeda estrangeira:

$$
\ln P^{*} X=(1+\alpha) \ln (C P / E)+\alpha \ln P W
$$

Considerando-se a versão não restrita da Equação (3), na qual não se exige que a soma dos coeficientes relativos a $\ln (C P / E)$ e $\ln (P W)$ seja igual a 1 e na qual se admite que os coeficientes relativos a $\ln (C P)$ e $\ln (E)$ difiram em sinal e magnitude, conforme Menon (1995), tem-se:

$$
\ln P^{*} X=\phi_{0}+\phi_{1} \ln C P+\phi_{2} \ln E+\phi_{3} \ln P W
$$

em que o coeficiente de pass-through é representado por $\phi_{2}$.

A análise do resultado deste coeficiente pode ser expressa da seguinte forma:

$\phi_{2}=0$; significa que a taxa de câmbio não exerce influência sobre o preço em moeda estrangeira dos bens exportados;

$\phi_{2}=-1$; significa que a mudança na taxa de câmbio afeta integralmente o preço em moeda estrangeira dos bens exportados e

$-1<\phi_{2}<0$; significa que a mudança na taxa de câmbio afeta parcialmente o preço em moeda estrangeira dos bens exportados. 


\section{Procedimentos Econométricos}

\section{Teste de Raiz Unitária}

Para determinar a ordem de integração das séries de interesse, este trabalho utilizou os testes de raiz unitária Dickey-Fuller Aumentado (DICKEY; FULLER, 1979, 1981) e Kwiatkowski et al. (1992). Esses testes permitem verificar a existência ou não de raízes unitárias nas séries temporais, ou seja, se as variáveis são ou não estacionárias. ${ }^{4}$

O teste ADF consiste na estimação da seguinte equação por Mínimos Quadrados Ordinários e pode ser expresso, conforme Enders (1995), da seguinte forma:

$$
\Delta y_{t}=\alpha_{0}+\gamma y_{t-1}+\sum_{i=2}^{p} \beta_{i} \Delta y_{t-i+1}+\varepsilon_{t}
$$

com: $\gamma=-\left(1-\sum_{i=1}^{p} \alpha_{i}\right)$ e $\beta_{i}=\sum_{j=i}^{p} \alpha_{j}$,

em que: $\alpha_{0}$ é o intercepto; $\gamma$ descreve o comportamento da série temporal; $y$ representa a variável dependente; $\Delta$ é a representação do operador de diferença e $\varepsilon_{t}$ denota o erro que se assume ser idêntica e independentemente distribuída. A fim de determinar o número de defasagens utilizadas no teste para eliminar a autocorrelação residual, utilizou-se o menor valor do critério de Schwarz (SBC).

O parâmetro de interesse nas regressões (sem intercepto e sem tendência; com intercepto; com intercepto e tendência) é $\gamma$, sendo que, se $\gamma=\mathbf{O}$, a série contém uma raiz unitária. Nesse teste compara-se o resultado da estatística $\tau$ com os valores apropriados reportados por Dickey-Fuller para determinar se aceita ou se rejeita a hipótese nula $\gamma=0$. A hipótese nula será rejeitada se o valor calculado da estatística $\tau$ for maior do que o valor crítico de Dickey-Fuller, indicando que a série é estacionária; caso contrário, a série é não estacionária.

O KPSS é um teste alternativo ao ADF, sendo definido pelo procedimento de um teste de não estacionariedade contra a hipótese nula de estacionariedade, conforme Greene (2008). Formalmente é expresso pela seguinte expressão:

$$
\begin{aligned}
& y_{t}=\alpha+\beta t+\gamma \sum_{i=1}^{t} z_{i}+\varepsilon_{t} \\
& y_{t}=\alpha+\beta_{t}+\gamma Z_{t}+\varepsilon_{t}
\end{aligned}
$$

tendo as seguintes hipóteses:

$H_{0}: \gamma=0$, série é estacionária

$H_{a}: \gamma \neq 0$, série é não estacionária

\footnotetext{
${ }^{4}$ Um processo estocástico é estacionário quando a sua média e a sua variância são constantes ao longo do tempo e quando o valor da covariância entre dois períodos de tempo depende apenas da distância, do intervalo ou da defasagem entre os períodos de tempo, e não do próprio tempo em que a covariância é calculada. Em notação matemática, as propriedades do processo estocástico estacionário podem ser representadas por: (Média) $E\left(Y_{t}\right)=\mu$, (Variância) $\operatorname{var}\left(Y_{t}\right)=E\left(Y_{t}-u\right)^{2}=\sigma^{2}$ e (Covariância) $\gamma_{k}=E\left[\left(Y_{t}-\mu \chi T_{t+k}-\mu\right]\right.$. Um processo estocástico com as propriedades descritas anteriormente é conhecido, na literatura de séries temporais, como processo fracamente estacionário, ou estacionário em covariância, ou estacionário de segunda ordem, ou estacionário em sentido amplo. Um processo estocástico é fortemente estacionário quando todos os momentos de sua distribuição não variam ao longo do tempo (BUENO, 2008).
} 


\section{Análise de Cointegração}

Mesmo que variáveis individuais não sejam estacionárias, mas exista pelo menos uma combinação linear estacionária entre elas, então é possível afirmar que essas variáveis são cointegradas (GREENE, 2008), ou seja, é possível verificar uma relação de equilíbrio de longo prazo entre elas, que pode ser estimada e analisada. ${ }^{5}$ Dessa forma, para identificar o possível relacionamento de longo prazo entre as séries, utilizou-se o teste de cointegração elaborado por Johansen (1988).

O procedimento de Johansen (1988) considera que todas as variáveis são endógenas e sua utilização não é limitada pela existência de endogeneidade do regressor (relação causal no sentido da variável dependente para a variável explicativa). Esse procedimento utiliza Máxima Verossimilhança para estimar os vetores de cointegração e permite testar e estimar a presença de vários vetores e não só de um único vetor de cointegração.

De acordo com Harris (1995), definido um vetor $z_{t}$ de $n$ variáveis potencialmente endógenas, é possível especificar o seguinte processo gerador, e modelar $z_{t}$ como um Vetor Auto-Regressivo (VAR) irrestrito com $\mathrm{k}$ defasagens de $z_{t}$ :

$$
z_{t}=A_{1} z_{t-1}+\ldots+A_{k} z_{t-k}+u_{t}
$$

em que: $z_{t}$ é um vetor (nx1), $A_{i}$ é uma matriz de parâmetros $(n x n)$ e $u_{t} \sim I I D\left(\mu, \sigma^{2}\right)$.

Ainda conforme Harris (1995), a Equação (7) pode ser reparametrizada em termos de um modelo Vetorial de Correção de Erro (VEC) esboçado como:

$$
\Delta z_{t}=\Gamma_{1} \Delta z_{t-1}+\ldots+\Gamma_{k-1} \Delta z_{t-k+1}+\prod z_{t-k}+\varepsilon_{t}
$$

em que: $\Gamma_{i}=-\left(I-A_{1}-\cdots-A_{i}\right),(\mathrm{i}=1, \ldots, \mathrm{k}-1)$ e $\Pi=-\left(I-A_{1}-\cdots A_{k}\right)$ Da forma como especificado, o sistema contém informações de curto e longo prazo a mudanças de $z_{t}$, via estimativas de $\hat{\boldsymbol{\Gamma}}_{i} \mathrm{e} \hat{\boldsymbol{I}}$, respectivamente, onde $\boldsymbol{D}=a \hat{a}^{\prime}, \operatorname{com} \alpha$ representando a velocidade de ajustamento ao desequilíbrio e $\beta$ a matriz de coeficientes de longo prazo.

A importância do modelo de correção de erro reside no fato de permitir a ligação entre aspectos relacionados à dinâmica de curto prazo com os de longo prazo (HAMILTON, 1994). Dessa forma, os mecanismos de correção de erro pretendem fornecer um caminho para combinar as vantagens de se modelar tanto em nível quanto nas diferenças. Nesse modelo não apenas a dinâmica do processo de ajustamento de curto prazo como também a do processo de longo prazo são modeladas simultaneamente.

O número de vetores de cointegração depende do posto ou rank $(r)$ da matriz $\Pi$. Em termos de vetores de cointegração, tem-se três possibilidades, conforme Enders (1995): se o posto de $\Pi$ é completo, então as variáveis $Y_{t}$ são I(0), ou seja, significa que qualquer combinação linear entre as variáveis é estacionária e o ajuste do modelo deve ser

\footnotetext{
${ }^{5}$ Engle e Granger (1987) mostram que, se todas as séries de interesse possuem a mesma ordem de integração $I(d)$ e existir um vetor $\alpha$, com $\alpha \neq 0$, em que a combinação linear dessas variáveis seja de ordem $d-b$, $Z_{t}=\alpha^{\prime} X_{t} \sim I(d-b), b>0$, pode-se afirmar que $X_{t}$ é um vetor de variáveis cointegradas denotadas por $X_{t} \sim \boldsymbol{C}(d, b)$.
} 
efetuado com as variáveis em nível; se o posto de $\Pi$ é zero, então não há relacionamento de cointegração e o modelo deve ser ajustado com as variáveis em diferença, e quando $\Pi$ tem posto reduzido, há $r$ vetores de cointegração.

Para Enders (1995), o rank de uma matriz é igual ao número de raízes características estritamente diferentes de zero, que pode ser identificado por meio de dois testes estatísticos. O primeiro deles é o teste do traço, que testa a hipótese nula de que o número de vetores de cointegração distintos é menor ou igual a $r$ contra a hipótese alternativa de que o número desses vetores é maior do que $r$, que pode ser definido por:

$$
\lambda_{\text {trace }}(r)=-T \sum_{i=r+1}^{n} \ln \left(1-\lambda_{i}^{\prime}\right)
$$

em que

$\lambda_{i}^{\prime}=$ valores estimados das raízes características obtidos da matriz $\Pi ; T=$ número de observações.

O segundo teste é o do máximo autovalor, que testa a hipótese nula de que o número de vetores de cointegração é $r$ contra a hipótese alternativa de existência de $r+1$ vetores de cointegração, podendo ser expresso da seguinte forma:

$$
\lambda_{\max }(r, r+1)=-T \ln \left(1-\lambda_{r+1}^{\prime}\right)
$$

Verificada a cointegração entre as séries analisadas, estima-se o modelo VEC, conforme definido na Expressão (8).

\section{Testes de Autocorrelação}

\section{Teste de Portmanteau}

O teste de Portmanteau calcula as estatísticas Box-Pierce/Ljung-Box multivariadas para correlação serial residual até a defasagem especificada.

Box e Pierce (1970) desenvolveram uma estatística Q baseada na soma dos quadrados das autocorrelações. A estatística de Box-Pierce $Q=T * \sum_{k=1}^{q} \rho_{k}^{2}$ é comparada à distribuição qui-quadrado com "q" graus de liberdade. Caso o resíduo seja um ruído branco, a estatística $\mathrm{Q}$ definida segue uma distribuição qui-quadrado com "q" graus de liberdade.

Ljung-Box (1978), também conhecido como teste de Box-Pierce modificado, é utilizado para verificar se há falha de ajuste em um modelo temporal. O teste examina as "n" primeiras autocorrelações dos resíduos e, caso estas sejam pequenas, há indício de que não há falha no ajuste. A hipótese nula desse teste considera que as autocorrelações até o lag "n" é igual a zero e a estatística do teste é definida pela Equação (11):

$$
Q^{*}=T *(T-2) \sum_{k}^{n} \frac{\hat{\rho}_{k}^{2}}{T-k}
$$

onde $\hat{\rho} k$ a autocorrelação estimada dos resíduos na defasagem " $\mathrm{k}$ " e " $\mathrm{n}$ " o número de lags testado. O teste irá rejeitar a hipótese nula caso $Q^{*}>\chi_{1-\alpha ; q}^{2}$, sendo $\chi_{1-\alpha ; q}^{2}$ uma distribuição qui-quadrado com "q" graus de liberdade e nível de significância $\alpha$. 


\section{Teste LM}

O teste de Breusch (1978) - Godfrey (1978), também conhecido como teste LM (Lagrange Multiplier) para autocorrelação, testa a hipótese nula de ausência de autocorrelação até a defasagem $p$. Após definir o modelo e estimar seus coeficientes, o teste consiste em efetuar uma regressão do resíduo contra o próprio resíduo defasado no tempo e as variáveis explicativas, de acordo com a Equação (12):

$$
\hat{u}_{t}=\alpha_{0}+\alpha_{1} x_{t}+\hat{\rho}_{1} \hat{u}_{t-1}+\hat{\rho}_{2} \hat{u}_{t-2}+\cdots+\hat{\rho}_{p} \hat{u}_{t-p}+v_{t}
$$

onde os últimos termos $\hat{u}_{t-1}, \hat{u}_{t-2}, \ldots, \hat{u}_{t-p}$ são os resíduos estimados pela equação do modelo adotado.

\section{Fonte dos Dados}

Os dados para estimação do modelo apresentado na Equação (4) foram coletados nos seguintes sites: no Instituto de Economia Aplicada - Ipea (2019), para as variáveis preço de exportação do grão de soja (preço médio recebido da soja em grão pelo agricultor do Paraná, em R\$ por saca $60 \mathrm{~kg}$, transformado em dólar por toneladas - US\$/toneladas e em euro por toneladas - $€$ /tonelada), custo de produção, utilizado como proxy o Índice de Preços ao Atacado - Disponibilidade Interna - IPA - DI, as taxas de câmbio nominal (em real/dólar - R\$/US\$ e em real/euro - R\$/€); e no World Bank (2019) para a variável preço internacional do grão de soja (grão de soja, número 2, preço CIF em Roterdã). O período analisado foi o de janeiro/2000 a dezembro/2018, com cotações mensais, totalizando 228 observações. Na Tabela 1 encontra-se um resumo das variáveis estimadas no modelo.

Tabela 1 - Variáveis estimadas no modelo e as respectivas siglas

\begin{tabular}{cc}
\hline Variável & Sigla \\
\hline Log preço de exportação do grão de soja em dólar & LBRA_SGD \\
Log preço de exportação do grão de soja em euro & LBRA_SGE \\
Log custo de produção no Brasil & LBRA_CP \\
Log taxa de câmbio real/dólar & LBRA_D \\
Log taxa de câmbio real/euro & LBRA_E \\
Log preço internacional do grão de soja em dólar & LINT_SGD \\
Log preço internacional do grão de soja em euro & LINT_SGE \\
\hline
\end{tabular}

Fonte: Organização dos autores.

Na seção seguinte será apresentada a análise e discussão dos resultados dos modelos para o grão de soja estimados em dólar e em euro.

\section{ANÁLISE E DISCUSSÃO DOS RESULTADOS}

Como forma de indicar a ordem de integração das séries de análise, foram aplicados dois testes de estacionariedade: ADF - Dickey- Fuller Aumentado; e KPSS - Kwiatkoswski, Philips, Schmidt e Shin. Os resultados estão expostos nas Tabelas 2 e 3. 
Tabela 2 - Testes de raiz unitária em nível aplicados nas séries mensais de preços de exportação do grão de soja (em US\$/toneladas e em €/toneladas), custo de produção, taxas de câmbio nominal (R\$/US\$ e R\$/€) e preços internacionais do grão de soja (US\$/toneladas e €/toneladas) no período de janeiro de 2000 a dezembro de 2018

\begin{tabular}{ccccccc}
\hline & \multicolumn{3}{c}{ Teste ADF } & \multicolumn{3}{c}{ Teste KPSS } \\
\hline Séries & Modelo & \multicolumn{2}{c}{ Estatística de teste } & Modelo & \multicolumn{2}{c}{ Estatística de teste } \\
\hline LBRA_SGD & constante & -1.921503 & ns & constante & 1.403577 & $* * *$ \\
LBRA_SGE & constante & -1.963875 & ns & constante & 1.510005 & $* * *$ \\
LBRA_CP & constante & -2.199909 & ns & constante & 1.901491 & $* * *$ \\
LBRA_D & constante & -1.348579 & ns & constante & 0.457308 & $*$ \\
LBRA_E & constante & -1.856183 & ns & constante & 0.681918 & $* *$ \\
LINT_SGD & constante & -1.857404 & ns & constante & 1.306875 & $* * *$ \\
LINT_SGE & constante & -1.925059 & ns & constante & 1.472334 & $* * *$ \\
\hline
\end{tabular}

Nota 1: *** significativo a $1 \%$; ** significativo a $5 \%$; $*$ significativo a $10 \%$; ns não significativo

Fonte: Elaboração própria com base nos dados da pesquisa.

Pela análise da Tabela 2 observa-se que todas as séries não foram estacionárias em nível, com $5 \%$ de significância para o teste $A D F$, ou seja, sua média, a variância ou ambas variam com o tempo. Já para o teste KPSS, as séries da taxa de câmbio (R\$/US\$ e $\mathrm{R} \$(€)$ foram estacionárias em nível, respectivamente, com $10 \%$ e $5 \%$ de significância. Por outro lado, os resultados da Tabela 3 indicam concordância em ambos os testes, efetuada a primeira diferença, as séries foram estacionárias, com $1 \%$ de significância.

Tabela 3 - Testes de raiz unitária em primeira diferença aplicados nas séries mensais de preços de exportação do grão de soja (em US\$/toneladas e em $€$ /toneladas), custo de produção, taxas de câmbio nominal (R\$/ US\$ e R\$়/ €) e preços internacionais do grão de soja (US\$/toneladas e

$€$ /toneladas) no período de janeiro de 2000 a dezembro de 2018

\begin{tabular}{ccccccc}
\hline & \multicolumn{3}{c}{ Teste ADF } & \multicolumn{3}{c}{ Teste KPSS } \\
\hline Séries & Modelo & \multicolumn{2}{c}{ Estatística de teste } & Modelo & Estatística de teste \\
\hline LBRA_SGD & constante & -10.13462 & $* * *$ & constante & 0.107344 & $\mathrm{~ns}$ \\
LBRA_SGE & constante & -11.44475 & $* * *$ & constante & 0.060418 & $\mathrm{~ns}$ \\
LBRA_CP & constante & -6.411110 & $* * *$ & constante & 0.325420 & $\mathrm{~ns}$ \\
LBRA_D & constante & -9.965397 & $* * *$ & constante & 0.134717 & $\mathrm{~ns}$ \\
LBRA_E & constante & -11.33721 & $* * *$ & constante & 0.093503 & $\mathrm{~ns}$ \\
LINT_SGD & constante & -11.87678 & $* * *$ & constante & 0.128123 & $\mathrm{~ns}$ \\
LINT_SGE & constante & -13.25732 & $* * *$ & constante & 0.064572 & $\mathrm{~ns}$ \\
\hline
\end{tabular}

Nota 1: *** significativo a $1 \%$; ${ }^{* *}$ significativo a $5 \%$; ${ }^{*}$ significativo a $10 \%$; ns não significativo

Fonte: Elaboração própria com base nos dados da pesquisa.

Efetuados os testes de estacionariedade das séries e identificada a ordem de integração, a próxima etapa consistiu em analisar individualmente a dinâmica do repasse cambial nos preços de exportação do grão de soja.

\section{Grão de Soja em Dólar}

Na Figura 1 é possível identificar a evolução do preço de exportação do grão de soja (em US\$/toneladas) e a taxa de câmbio nominal (R\$/US\$) de janeiro de 2000 até dezembro de 2018. 
Figura 1 - Relação entre preço de exportação do grão de soja (em US\$/ toneladas) e a taxa de câmbio nominal (R\$/US\$), no período de janeiro de 2000 a dezembro de 2018

700

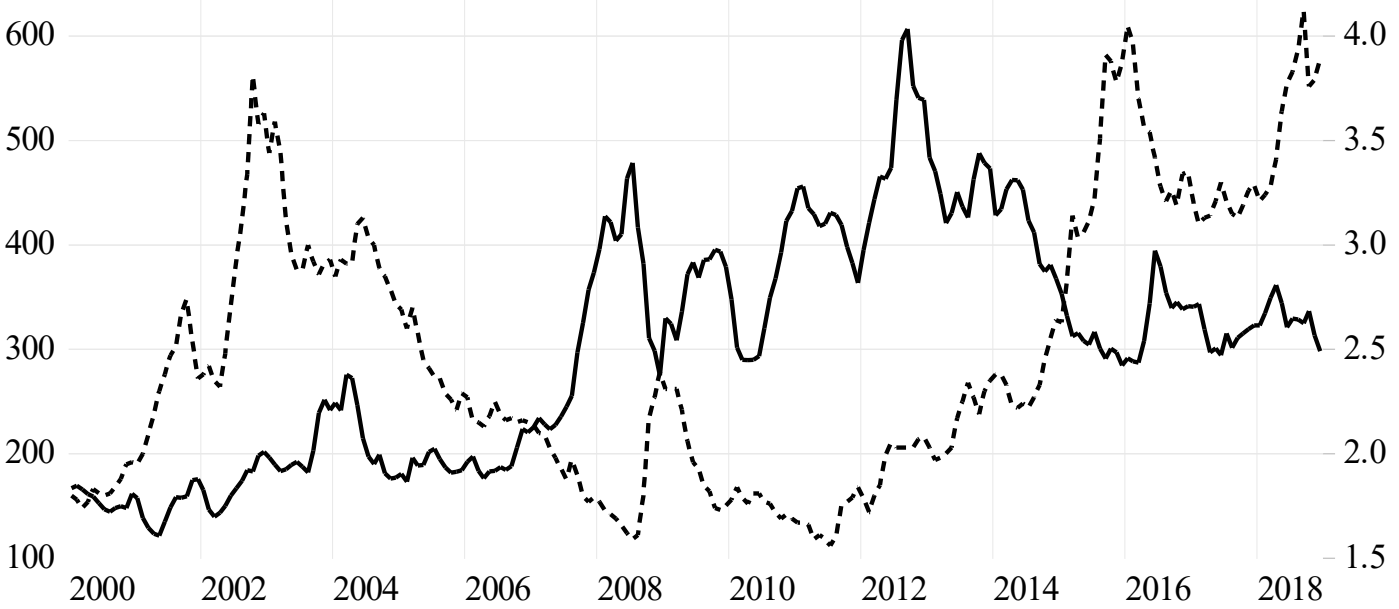

Fonte: Elaborado pelos autores a partir de IPEA (2019)

A partir da Figura 1 identificou-se que as séries apresentam uma tendência estocástica, ou seja, um padrão aleatório ao longo do tempo. É possível, contudo, que os dados apresentem um relacionamento de longo prazo a ser confirmado pelo teste de cointegração.

Para realização do teste de cointegração é necessário verificar o número de defasagens para inserir do modelo (Tabela 4).

Tabela 4 - Critério de defasagem do VAR auxiliar para o grão de soja em dólar

\begin{tabular}{ccccccc}
\hline Defasagem & LogL & LR & FPE & AIC & BIC & HQ \\
\hline 0 & 289.1284 & NA & $9.21 \mathrm{e}-07$ & -2.545790 & -2.484867 & -2.521198 \\
1 & 1914.734 & 3178.640 & $5.28 \mathrm{e}-13$ & -16.91727 & -16.61266 & -16.79431 \\
2 & 2023.485 & 208.7637 & $\mathbf{2 . 3 1 e - 1 3 *}$ & $\mathbf{- 1 7 . 7 4 5 4 1 *}$ & $\mathbf{- 1 7 . 1 9 7 1 1 ^ { * }}$ & $\mathbf{- 1 7 . 5 2 4 0 8 *}$ \\
3 & 2030.020 & 12.31097 & $\mathbf{2 . 5 1 e - 1 3}$ & -17.66089 & -16.86890 & -17.34121 \\
4 & 2045.725 & $\mathbf{2 9 . 0 2 5 5 7 *}$ & $\mathbf{2 . 5 2 e - 1 3}$ & -17.65826 & -16.62258 & -17.24021 \\
\hline
\end{tabular}

Nota 1: valor da verossimilhança (LogL); $p$-valor do teste de razão de verossimilhança (LR); Erro de Predição Final (FPE); Critério de Informação de Akaike (AIC); Critério de Informação Bayesiano de Schwarz (BIC); e o Critério de Informação de Hannan \& Quinn (HQC).

Nota 2: *indica a defasagem ótima ( $n$ ) definida pelo critério.

Fonte: Elaboração própria com base nos dados da pesquisa.

Com base nos dados da Tabela 4 foi possível identificar o número de defasagens ótimas a incluir no VAR. Selecionaram-se 4 (quatro) defasagens como forma de melhor ajuste no modelo, pois com 2 (duas) defasagens, o modelo apresentou autocorrelação nos resíduos, indicando não ajustamento, que, segundo Greene (2008), pode estar relacionado a variáveis que deveriam ser acrescentadas no modelo econométrico. Ainda nesta perspectiva, para Barros e Souza (1995), isso significa que devem ser incluídas defasagens adicionais nas variáveis já presentes no modelo. 
O teste de cointegração de Johansen revelou que a hipótese nula de que não há nenhum vetor de cointegração deve ser rejeitada ao nível de $5 \%$ para a estatística do traço e para a estatística do máximo autovalor (de acordo com os dados da Tabela 5). Além disso, o modelo da equação de cointegração que mais se ajustou ao teste foi o modelo 5 do sumário do teste, com as variáveis em nível com tendência quadrática e as equações de cointegração com tendência linear.

Tabela 5 - Teste de cointegração de Johansen para o grão de soja em dólar

\begin{tabular}{ccccc}
\hline & \multicolumn{2}{c}{ Estatística do Traço } & \multicolumn{2}{c}{ Estatística do Máximo Autovalor } \\
\hline $\mathbf{R}=\mathbf{0}$ & Calculado & P-valor & Calculado & P-valor \\
$\mathrm{R} \leq 1$ & $\mathbf{5 6 . 8 3 0 7 8 * *}$ & $\mathbf{0 . 0 3 6 0}$ & $\mathbf{3 0 . 9 2 7 2 4 * *}$ & $\mathbf{0 . 0 4 8 5}$ \\
$\mathrm{R} \leq 2$ & 25.90354 & 0.3324 & 14.16933 & 0.5720 \\
$\mathrm{R} \leq 3$ & 11.73420 & 0.3292 & 9.299422 & 0.4649 \\
\hline
\end{tabular}

Nota: $* *$ significativo a $5 \% \mathrm{e}^{* * *}$ significativo a $1 \%$.

Fonte: Elaboração própria com base nos dados da pesquisa.

De acordo com a Tabela 6, que apresenta o vetor de cointegração (normalizado), todos os coeficientes estimados foram significativos ao nível de $1 \%$.

Tabela 6 - Estimativa do vetor de cointegração (normalizado) para o grão de soja em dólar

\begin{tabular}{cccccc}
\hline LBRA_SGD (-1) & LBRA_CP (-1) & LBRA_D (-1) & LINT_SGD (-1) & @TREND(00M01) & C \\
\hline 1,0000 & $0.892629 * * *$ & $-0.293854 * * *$ & $-1.436282^{* * *}$ & -0.003864 & -1.878558 \\
& $(0.17474)$ & $(0.08471)$ & $(0.09607)$ & - & - \\
& {$[5.10841]$} & {$[-3.46879]$} & {$[-14.9497]$} & - & - \\
\hline
\end{tabular}

Nota I: LBRA_SGD = logaritmo neperiano do preço de exportação do grão de soja em dólar (US\$/toneladas); LBRA CP = logaritmo neperiano do custo de produção; LBRA_E = logaritmo neperiano da taxa de câmbio (R\$/ US\$); LINT_SGD = logaritmo neperiano do preço internacional do grão de soja (US\$/toneladas); @TREND(00M01)= tendência; $\mathrm{C}=$ constante. Nota 2: os valores entre parênteses referem-se ao erro padrão, e os entre colchetes, à estatística t. Nota 3: $* * *$ significativo a $1 \%{ }^{* *}$ significativo a $5 \%$, ns não significativo.

Fonte: Elaboração própria com base nos dados da pesquisa.

Na Equação (13) é apresentado o vetor de cointegração (normalizado), indicando o relacionamento de longo prazo entre as variáveis com as respectivas elasticidades.

$L B R A_{-} S G D_{t}=-0,89$ LBRA_CP + 0,29LBRA_D + 1,44 LINT_SGD $+0,004 @ T R E N D(O O M O 1)+1,88$

De acordo com a Equação (13), verifica-se que o coeficiente de pass-through foi incompleto, indicando que a variação da taxa de câmbio (R\$/US\$) influencia parcialmente o preço de exportação do grão de soja brasileiro cotado em dólar, ou seja, o aumento de $1 \%$ na taxa de câmbio ocasiona um aumento de $0,29 \%$ no preço de exportação do grão de soja.

Os estudos remontados na literatura revisada, que também encontraram um pass-through incompleto em relação ao grão de soja e os coeficientes estimados, foram de Fraga et al. (2008), -0,34, e Copetti, Vieira e Coronel (2012), -0,11. Demais estudos revisados sobre o repasse das variações da taxa de câmbio aos preços de exportação brasileiros também corroboraram o resultado de um pass-through incompleto (CRUZ JR.; SILVA, 2004, TEJADA; SILVA, 2008, CORREA, 2012; SOUZA; RANIRO; ROSA, 2018; SOUZA, 2018). 
Ainda, de acordo com a Equação (13), o aumento de 1\% no custo de produção brasileiro ocasiona uma diminuição de $0,89 \%$ no preço de exportação do grão de soja em dólar.

Também foi possível inferir, com base na Equação (13), que o aumento de $1 \%$ no preço internacional do grão de soja em dólar determina um aumento de 1,44\% no preço de exportação do grão de soja em dólar.

$O$ resultado encontrado na presente pesquisa sugere um coeficiente elástico na transmissão de preços e valida a Lei do Preço Único, que, de acordo com Mundlack e Larson (1992), bens idênticos, em regiões distintas, em livre concorrência de mercado, devem ser vendidos pelo mesmo preço. Outros estudos revisados sobre elasticidade de transmissão de preço também corroboraram este resultado de um coeficiente elástico na transmissão do preço internacional ao mercado brasileiro (MARGARIDO; TUROLLA; FERNANDES, 2001; MARGARIDO; FERNANDES; TUROLLA, 2002; MARGARIDO, TUROLLA; BUENO, 2007; MARGARIDO, 2012).

Com a finalidade de diagnóstico do modelo, foram estimados dois testes de correlação serial para os resíduos, cujos resultados encontram-se na Tabela 7.

Tabela 7 - Testes de correlação serial para os resíduos do modelo VEC para o grão de soja em dólar

\begin{tabular}{ccccccc}
\hline \multicolumn{4}{c}{ Teste de Portmanteau } & \multicolumn{2}{c}{ Teste LM } \\
\hline Defasagens & Est. Q & p-valor & Est Ajust.Q & p-valor & Est. LM & p-valor \\
\hline 1 & 0.246926 & --- & 0.248039 & --- & 8.466544 & 0.9337 \\
2 & 0.908250 & --- & 0.915348 & --- & 12.66032 & 0.6974 \\
3 & 2.292560 & --- & 2.318534 & --- & 17.53954 & 0.3515 \\
4 & 6.908754 & --- & 7.019042 & --- & 15.69293 & 0.4746 \\
5 & 15.68193 & 0.9703 & 15.99344 & 0.9659 & 11.84716 & 0.7544 \\
6 & 20.50581 & 0.9990 & 20.95070 & 0.9988 & 5.858304 & 0.9896 \\
7 & 39.12890 & 0.9831 & 40.17731 & 0.9770 & 19.52727 & 0.2423 \\
8 & 59.75070 & 0.9147 & 61.56644 & 0.8848 & 22.77441 & 0.1199 \\
9 & 73.50694 & 0.9218 & 75.90121 & 0.8877 & 14.86828 & 0.5343 \\
10 & 95.55435 & 0.7984 & 98.98371 & 0.7210 & 22.71289 & 0.1216 \\
11 & 114.8716 & 0.7095 & 119.3032 & 0.6024 & 21.03467 & 0.1772 \\
12 & 122.0252 & 0.8607 & 126.8637 & 0.7796 & 7.937707 & 0.9507 \\
\hline
\end{tabular}

Fonte: Elaboração própria com base nos dados da pesquisa.

Com base na análise dos dados apresentados na Tabela 7, até 12 defasagens 0 teste indica a rejeição da hipótese nula de que a correlação serial é diferente de zero, com $5 \%$ de significância. Desta forma, os resultados de diagnóstico do modelo estimado são válidos e apresentam um relacionamento correto e confiável entre as variáveis em questão.

\section{Grão de Soja em Euro}

Na Figura 2 é possível identificar a evolução do preço de exportação do grão de soja (em $€ /$ toneladas) e a taxa de câmbio nominal (R\$/€) de janeiro de 2000 até dezembro de 2018. 
Figura 2 - Relação entre o preço de exportação do grão de soja (em € /toneladas) e a taxa de câmbio nominal (Real/ Euro - R\$̦/€), no período de janeiro de 2000 a dezembro de 2018

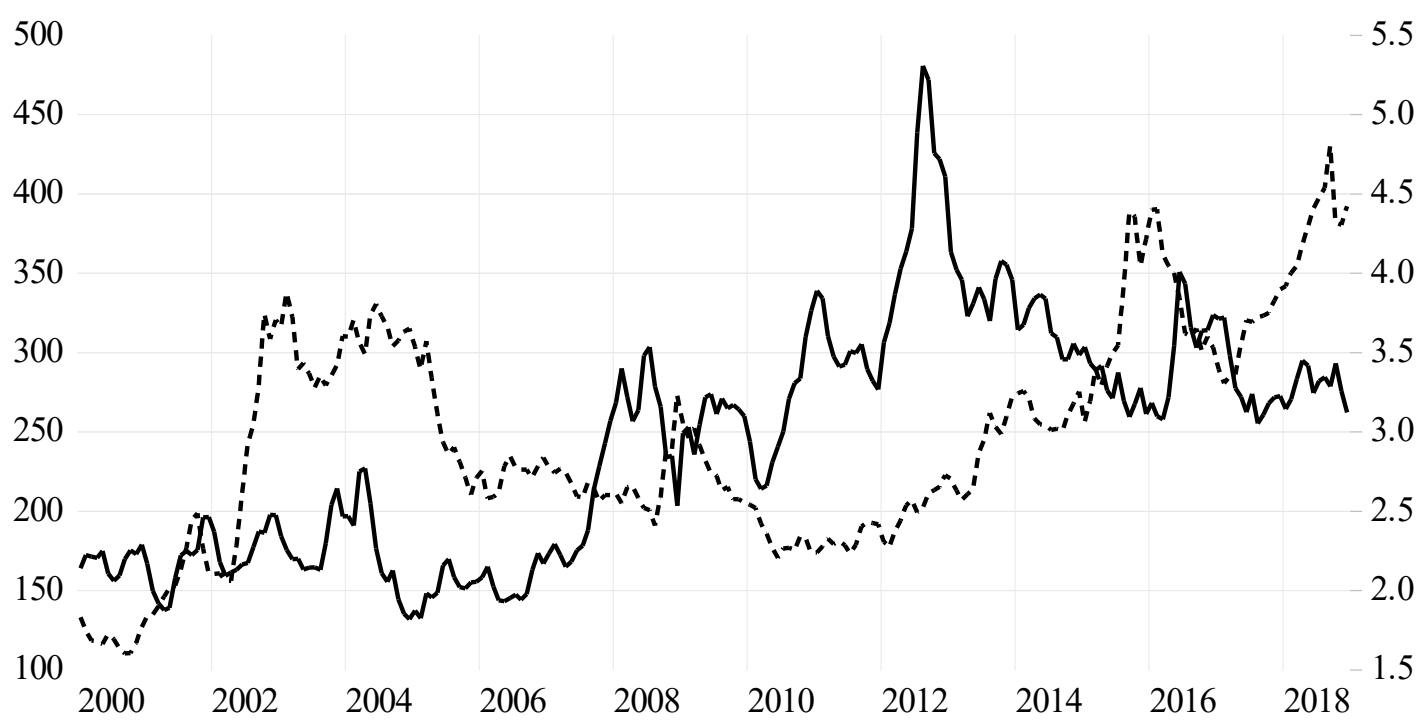

Fonte: Elaborado pelos autores a partir de IPEA (2019).

A partir da Figura 2 identifica-se que as séries apresentam uma tendência estocástica, ou seja, um padrão aleatório ao longo do tempo. É possível, contudo, que os dados apresentem um relacionamento de longo prazo a ser confirmado pelo teste de cointegração.

Para realização do teste de cointegração, é necessário verificar o número de defasagens para inserir do modelo (Tabela 8).

Tabela 8 - Critério de defasagem do VAR auxiliar para o grão de soja em euro

\begin{tabular}{ccccccc}
\hline Defasagem & LogL & LR & FPE & AIC & BIC & HQ \\
\hline 1 & 1910.010 & NA & $5.32 \mathrm{e}-13$ & -16.91081 & -16.66712 & -16.81244 \\
2 & 2008.282 & 189.5249 & $\mathbf{2 . 5 5 e - 1 3 *}$ & $\mathbf{- 1 7 . 6 4 5 3 8 *}$ & $\mathbf{- 1 7 . 1 5 8 0 0 *}$ & $\mathbf{- 1 7 . 4 4 8 6 5 *}$ \\
3 & 2013.417 & 9.718592 & $2.81 \mathrm{e}-13$ & -17.54836 & -16.81730 & -17.25327 \\
4 & $\mathbf{2 0 2 8 . 2 2 9}$ & $\mathbf{2 7 . 5 0 7 5 4 *}$ & $\mathbf{2 . 8 4 e - 1 3}$ & -17.53775 & -16.56300 & -17.14430 \\
\hline
\end{tabular}

Nota 1: valor da verossimilhança (LogL); $p$-valor do teste de razão de verossimilhança (LR); Erro de Predição Final (FPE); Critério de Informação de Akaike (AIC); Critério de Informação Bayesiano de Schwarz (BIC); e o Critério de Informação de Hannan \& Quinn (HQC).

Nota 2: *indica a defasagem ótima ( $n$ ) definida pelo critério.

Fonte: Elaboração própria com base nos dados da pesquisa.

Com base nos dados da Tabela 8 foi possível indicar que o número de defasagens é de 2 (duas) a ser incluída no VAR, visto que, dos cinco critérios considerados, quatro indicaram mesmo número de defasagens do VAR auxiliar.

O teste de cointegração de Johansen revelou que a hipótese nula de que não há nenhum vetor de cointegração deve ser rejeitada ao nível de $1 \%$ (de acordo com os dados da Tabela 9). Além disso, o modelo da equação de cointegração que mais se ajustou ao teste foi o modelo 4 do sumário do teste, com as variáveis em nível e as equações de cointegração com tendência linear e as equações de cointegração com interceptos. 
Tabela 9 - Teste de cointegração de Johansen para o grão de soja em euro

\begin{tabular}{ccccc}
\hline & \multicolumn{2}{c}{ Estatística do Traço } & \multicolumn{2}{c}{ Estatística do Máximo Autovalor } \\
\hline $\mathbf{R}=\mathbf{0}$ & Calculado & P-valor & Calculado & P-valor \\
$\mathrm{R} \leq 1$ & $\mathbf{7 3 . 0 3 7 1 9 * * *}$ & $\mathbf{0 . 0 0 7 0}$ & $\mathbf{4 0 . 0 7 2 6 0 * * *}$ & $\mathbf{0 . 0 0 4 3}$ \\
$\mathrm{R} \leq 2$ & 32.96459 & 0.3382 & 17.37864 & 0.4264 \\
$\mathrm{R} \leq 3$ & 15.58595 & 0.5261 & 11.58048 & 0.4552 \\
\hline
\end{tabular}

Nota: $* *$ significativo a $5 \%$ e $* * *$ significativo a $1 \%$

Fonte: Elaboração própria com base nos dados da pesquisa.

De acordo com a Tabela 10, que apresenta o vetor de cointegração (normalizado), todos os coeficientes estimados foram significativos ao nível de $1 \%$.

Tabela 10 - Estimativa do vetor de cointegração (normalizado) para o grão de soja em euro

\begin{tabular}{cccccc}
\hline LBRA_SGE (-1) & LBRA_CP (-1) & LBRA_E (-1) & LINT_SGE (-1) & @TREND(00M01) & C \\
\hline 1,0000 & $0.768381^{* * *}$ & $-0.326142^{* * *}$ & $-1.473076^{* * *}$ & $-0.002865^{* * *}$ & -1.022804 \\
& $(0.15949)$ & $(0.08603)$ & $(0.09187)$ & $(0.00077)$ & - \\
& {$[4.81763]$} & {$[-3.79102]$} & {$[-16.0341]$} & {$[-3.71995]$} & - \\
\hline
\end{tabular}

Nota I: LBRA_SGE = logaritmo neperiano do preço de exportação do grão de soja em euro (em €/toneladas); LBRA_CP = logaritmo neperiano do custo de produção; LBRA_E = logaritmo neperiano da taxa de câmbio (RŚ/ €); LINT_SGE = logaritmo neperiano do preço internacional do grão de soja em euro (€/toneladas); @TREND(00M01) = tendência; C = constante. Nota 2: os valores entre parênteses referem-se ao erro padrão, e os entre colchetes, à estatística t. Nota $3: * * *$ significativo a $1 \% ; * *$ significativo a $5 \%$, ns não significativo.

Fonte: Elaboração própria com base nos dados da pesquisa.

Na Equação (14), é apresentado o vetor de cointegração (normalizado), indicando o relacionamento de longo prazo entre as variáveis com as respectivas elasticidades.

LBRA_SGE $=-0,77$ LBRA_CP $+0,33$ LBRA_E +1,47LINT_SGE $+0,003 @ T R E N D(00 M 01)+1,02$

De acordo com a Equação (14), verifica-se que o coeficiente de pass-through foi incompleto, indicando que a variação da taxa de câmbio influencia parcialmente o preço de exportação do grão de soja em euro, ou seja, o aumento de $1 \%$ na taxa de câmbio (R\$/€) ocasiona um aumento de $0,33 \%$ no preço de exportação do grão de soja em euro. O resultado de pass-through incompleto também foi encontrado em diversos estudos sobre as exportações brasileiras já citados anteriormente tanto para o grão de soja quanto para outros produtos e setores, corroborando a presente pesquisa (CRUZ JR.; SILVA, 2004; TEJADA; SILVA, 2008; FRAGA et al., 2008; CORREA, 2012; COPETTI, VIEIRA; CORONEL, 2012; SOUZA, RANIRO; ROSA, 2018; SOUZA, 2018). Por outro lado, este resultado difere do realizado por Copetti; Vieira e Coronel (2013), que também utiliza-

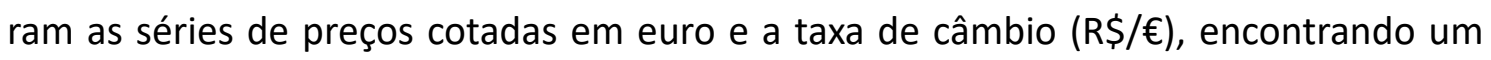
coeficiente de pass-through nulo, indicando que a taxa de câmbio (R\$/€) não exerce influência sobre os preços de exportação do grão de soja (em €/toneladas), porém destaca-se que o período de análise por estes autores foi distinto do adotado na presente pesquisa.

Ainda, o aumento de $1 \%$ no custo de produção brasileiro ocasiona uma diminuição de $0,77 \%$ no preço de exportação do grão de soja em euro. 
Também é possível inferir que o aumento de $1 \%$ no preço internacional do grão de soja em euro determina um aumento de $1,47 \%$ no preço de exportação do grão de soja em euro brasileiro.

Com a finalidade de diagnóstico do modelo, foram estimados testes de correlação serial para os resíduos, cujos resultados encontram-se na Tabela 11.

Tabela 11 - Teste de correlação serial para os resíduos do modelo VEC para o grão de soja em euro

\begin{tabular}{ccccccc}
\hline \multicolumn{5}{c}{ Teste de Portmanteau } & \multicolumn{2}{c}{ Teste LM } \\
\hline Defasagens & Est. Q & p-valor & Est Ajust.Q & p-valor & Est. LM & -valor \\
\hline 1 & 0.497907 & --- & 0.500130 & -- & 24.12967 & 0.0867 \\
2 & 5.776659 & --- & 5.826225 & --- & 20.36285 & 0.2043 \\
3 & 23.40222 & 0.7578 & 23.68997 & 0.7441 & 23.97872 & 0.0900 \\
4 & 37.13286 & 0.7915 & 37.66913 & 0.7727 & 15.31508 & 0.5017 \\
5 & 50.61208 & 0.8260 & 51.45470 & 0.8031 & 14.49369 & 0.5620 \\
6 & 59.30625 & 0.9329 & 60.38706 & 0.9184 & 9.076653 & 0.9102 \\
7 & 77.59528 & 0.8747 & 79.26335 & 0.8442 & 18.59788 & 0.2901 \\
8 & 102.5695 & 0.6551 & 105.1583 & 0.5863 & 26.10405 & 0.0526 \\
9 & 119.4844 & 0.6224 & 122.7780 & 0.5395 & 18.12824 & 0.3164 \\
10 & 142.2521 & 0.4546 & 146.6046 & 0.3561 & 24.15499 & 0.0862 \\
11 & 160.5846 & 0.4058 & 165.8795 & 0.2983 & 19.47728 & 0.2447 \\
12 & 169.9696 & 0.5509 & 175.7932 & 0.4265 & 9.645519 & 0.8845 \\
\hline
\end{tabular}

Fonte: Elaboração própria com base nos dados da pesquisa.

Com base na análise dos dados apresentados na Tabela 11, até 12 defasagens o teste indica a rejeição da hipótese nula de que a correlação serial é diferente de zero, com $5 \%$ de significância. Desta forma, os resultados de diagnóstico do modelo estimado são válidos e apresentam um relacionamento correto e confiável entre as variáveis em questão.

\section{CONCLUSÕES}

O trabalho realizou uma investigação da influência da variação da taxa de câmbio aos preços de exportação do grão de soja em dólar e em euro. Nesse tocante, os resultados encontrados forneceram indicações de que o grau de pass-through da taxa de câmbio (em R\$/US\$ e em R\$/€) para os preços de exportação do grão de soja foi incompleto com os coeficientes para dólar e euro de, respectivamente, -0,29 e -0,33.

A partir disso, pode-se inferir que o coeficiente de pass-through encontrado determina que depreciações da taxa de câmbio não se traduzem em ganhos significativos de competitividade, dado que não reduzem expressivamente os preços de exportação.

Desse modo, como as variações cambiais determinaram reduzidos efeitos sobre a competitividade do grão de soja, cabe um enfoque sobre aspectos como o grau de concorrência na formação de preços desse mercado (pricing to market) e a elasticidade-preço da demanda. Logo, as características do mercado do grão de soja, como a elevada concentração, porém com reduzido poder de mercado dos exportadores devido ao crescimento da renda mundial, tem possivelmente minimizado o ajuste dos preços decorrentes de depreciações cambiais. 
Entre as limitações do presente trabalho está o fato de o coeficiente de pass-through estimado ser estático, ou seja, permitiu a análise geral de um período específico de tempo, não compreendendo o dinamismo da taxa de câmbio e sua influência período a período sobre os preços do mercado doméstico e de exportação. Assim sendo, recomenda-se, para estudos posteriores, o comparativo em subperíodos, bem como a aplicação do filtro de Kalman, como forma de captar a dinâmica do repasse cambial.

\section{REFERÊNCIAS}

BARROS, M.; SOUZA, R. C. Regressão dinâmica. Núcleo de Estatística Computacional. Rio de Janeiro: PUC-RJ, 1995.

BOX, G. E. P.; PIERCE, D. A. Distribution of Residual Autocorrelations in Autoregressivelntegrated Moving Average Time Series Models. Journal of the American Statistical Association, v. 65, n. 332, p. 1.509-1.526, 1970.

BREUSCH, T. S. Testing for autocorrelation in dynamic linear models. Australian Economic Papers, 17, 1978.

BUENO, R. D. L. D. Econometria de séries temporais. São Paulo: Cengage Learning, 2008.

COPETTI, L. S.; VIEIRA, K. M.; CORONEL, D. A. Transmissão das variações da taxa de câmbio para os preços de exportação da soja no Brasil e na Argentina. Custos e Agronegócios On-line, Recife, v. 8, n. 3, p. 113132, jul./ set. 2012.

COPETTI, L. S.; VIEIRA, K. M.; CORONEL, D. A. Transmissão da variação da taxa de câmbio para os preços de exportação da soja em grão: análise dos mercados dos Estados Unidos, do Brasil e da Argentina. Revista em Agronegócios e Meio Ambiente, v. 6, n. 3, p. 435-461, set./dez. 2013.

CORREA, A. L. Taxa de câmbio e preços de exportação no Brasil: avaliação empírica dos coeficientes de pass-through setoriais. Economia e Sociedade, Campinas, v. 21, n. 1 (44), p. 61-91, abr. 2012.

CRUZ JR., J. C.; SILVA, O. M. Pass-through da taxa de câmbio nos preços de exportação dos produtos agropecuários brasileiros: 1994-2003. In: CONGRESSO BRASILEIRO DE ECONOMIA E SOCIOLOGIA RURAL (SOBER), 42., 2004, Cuiabá. Anais [...]. Cuiabá, MT, 2004.

DICKEY, D. A.; FULLER, W. A. Distribution of the estimators for autoregressive time series with a unit root. Journal of the American Statistical Association, v. 74, n. 366, p. 427-431, 1979.

DICKEY, D. A.; FULLER, W. A Likelihood ratio statistics for autoregressive time series with a unit root. Econometrica, v. 49, p. 1.057-1.073, 1981.

ENDERS, W. Applied Econometric Time Series. Nova York: John Wiley \& Sons, 1995.

ENGLE, R. F.; GRANGER, C. W. Co-integration and error-correction: representation, estimation and testing. Econometrica, Chicago, v. 55, n. 2, p. 251-276, 1987.

FERREIRA, A.; SANSO, A. Exchange rate pass-through: the case of Brazilian exports of manufactures. In: WORLD CONGRESS OF THE INTERNATIONAL ECONOMIC ASSOCIATION, 2., 1999, Buenos Aires, ago. 1999. FRAGA, G. J. et al. O pass-through das variações da taxa de câmbio para os preços de exportação de soja. Revista Análise Econômica, Porto Alegre, n. 49, p. 193-210, 2008.

GODFREY, L. G. Testing for higher order serial correlation in regression equations when the regressors include lagged dependent variables. Econometrica, v. 46, n. 6, p. 1.303-1.310, nov. 1978.

GREENE, W. H. Econometrics Analysis. 6. ed. New Jersey: Pearson Education, 2008.

HAMILTON, J. D. Time series analysis. New Jersey: Princeton University Press, 1994.

HARRIS, R. I. D. Using cointegration analysis in econometric modelling. London: Prentice-Hall-Harvester Wheatsheaf, 1995.

IPEA. Instituto de Pesquisa Econômica Aplicada. Disponível em: http://www.ipeadata.gov.br/. Acesso em: 14 jan. 2019.

JOHANSEN, S. Statistical analysis of cointegration vectors. Journal of Economic Dynamic and Control, v. 12, p. 231-254, 1988.

KWIAKOWSKI, D. et al. Testing the alternative of stationary against the alternative of a unit root: how sure are we that economic time series have a unit root? Journal of Econometrics, p. 159-178, 1992.

MARGARIDO, M. A.; TUROLLA, F. A.; FERNANDES, J. M. Análise da elasticidade de transmissão de preços no mercado internacional de soja. Pesquisa \& Debate, SP, v. 12, n. 2(20), p. 5-40, 2001.

MARGARIDO, M. A.; FERNANDES, J. M.; TUROLLA, F. A. Análise da formação de preços no mercado internacional de soja: o caso do Brasil. Agricultura em São Paulo, São Paulo, v. 49, p. 71-85, 2002. 
MARGARIDO, M. A.; TUROLLA, F. A.; BUENO, C. R. F. The world market for soybeans: price transmission into Brazil and effects from the timing of crop and trade. Nova Economia, Belo Horizonte, v. 17, n. 2, p. 241-270, 2007.

MARGARIDO, M. A. Análise da transmissão espacial de preços no mercado internacional de soja. Revista de Economia e Administração, São Paulo, v. 11, n. 3, p. 281-303, 2012.

MENON, J. Exchange rate and import prices for a small open economy. Applied Economics, v. 27, n. 3, p. 297-301, 1995.

MDIC. Ministério de Desenvolvimento, Indústria e Comércio Exterior. Balança Comercial. Disponível em: http://www.mdic.gov.br/index.php/balanca-comercial. Acesso em: 10 mar. 2019.

MUNDLACK, Y.; LARSON, D. F. On the transmission of world agricultural prices. The World Bank Review, v.6, n.1, p.399-422, 1992.

RAVALLION, M. Testing market integration. American Journal of Agricultural Economics, v. 68, n.1, p. 102109, Feb. 1986

SOUZA, D. K. F. O impacto das variações cambiais nas exportações do milho e do algodão. 2018, 95 f. Dissertação (Mestrado em Economia) - Universidade Federal de São Carlos, Sorocaba, 2018.

SOUZA, D. K. F.; RANIRO, L. R.; ROSA, M. B. Análise do pass-through da taxa de câmbio para os preços de exportação do açúcar. In: CONGRESSO DA SOCIEDADE BRASILEIRA DE ECONOMIA, ADMINISTRAÇÃO E SOCIOLOGIA RURAL - SOBER, 56., 2018, Campinas. Anais [...]. Campinas, SP, 2018.

TEJADA, C. A. O.; SILVA, A. G. O pass-through das variações da taxa de câmbio para os preços dos principais produtos exportados pelo Brasil. Revista de Economia e Sociologia Rural, v. 46, n. 1, p. 171-205, jan./ mar. 2008.

USDA. United States Department of Agriculture. Custom Query. Disponível em: https://apps.fas.usda.gov/ psdonline/app/index.html\#/app/advQuery. Acesso em: 3 jan. 2019.

WORLD BANK. World Bank Commodity Price Data. Disponível em: pubdocs.worldbank.org/ en/561011486076393416/CMO-Historical-Data-Monthly.xlsx. Acesso em: 1ㅇ mar. 2019. 